\title{
CONTEXTUALIZAÇÃO HISTÓRICA DOS ESTUDOS DE FARADAY SOBRE ELETRICIDADE E MATÉRIA: CONTRIBUIÇÕES PARA O ENSINO DE CIÊNCIAS
}

\section{HISTORICAL CONTEXT OF THE FARADAY STUDIES ON ELECTRICITY AND MATTER: CONTRIBUTIONS FOR THE TEACHING OF SCIENCES}

\author{
Everton Santos Oliveira \\ Universidade Federal de Sergipe - UFS, Cidade Univ. Prof. José Aloísio de Campos, \\ everton.quimica2011@gmail.com
}

Nirly Araújo dos Reis

Universidade Federal de Sergipe - UFS, Campus Prof. Alberto Carvalho, nirly-reis@gmail.com

\section{Erivanildo Lopes da Silva}

Universidade Federal de Sergipe - UFS, Cidade Univ. Prof. José Aloísio de Campos, erivanildolopes@gmail.com

\section{Resumo}

Esse trabalho tem como objetivo apresentar os constructos teóricos de Michael Faraday sobre a natureza elétrica da matéria e sua possível contribuição para o Ensino de Ciências através da Abordagem Contextual. Tal pesquisa nos forneceu elementos que resultaram em categorias que apontam para as influências externas na produção do conhecimento científico, dos mecanismos que teorizam a constituição da matéria e questões que permitem traçar uma relação entre composição da matéria e eletricidade. Os dados analisados evidenciam aproximações entre as ideias dos estudantes e as deste cientista em conjunto com seus contemporâneos. Logo, acreditamos na relevância da inserção da Abordagem Contextual no ensino deste tópico, uma vez que há a possibilidade de utilizar-se dessas ideias a fim de estabelecer relações com as mais variadas concepções dos estudantes, processo que pode favorecer a construção de uma visão mais coerente da Ciência e do significado e aplicação de suas teorias.

Palavras-chave: História e Filosofia da Ciência, Michael Faraday, matéria, eletricidade.

\section{Abstract}

The objective of this study was to present the theoretical constructos of Michael Faraday about the electric nature of matter and its possible contribution to the Teaching of Science through the Contextual Approach. This research has provided us with elements that have resulted in categories that point to external influences in the production of scientific knowledge, mechanisms that theorize the constitution of matter and questions that allow 
us to establish a relation between the composition of matter and its relation with electricity. This research has provided us with elements that have resulted in categories that point to external influences on the production of scientific knowledge, mechanisms that theorize the constitution of matter and questions that allow us to establish a relationship between the composition of matter and its relation to electricity. Data analysis showed approximations between the ideas of the students and those of the scientist in conjunction with his contemporaries. Therefore, we believe in the relevance of the insertion of the Contextual Approach in the teaching of this topic, since it is possible to use these ideas to establish relations with the most varied conceptions of students, a process that favor the construction of more coherence of Science and the meaning and application of their theories.

Keywords: History and Philosophy of Science, Michael Faraday, Matter, electricity.

\section{Introdução}

Nas últimas décadas um dos objetivos do Ensino de Ciências é a formação de cidadãos capazes de estabelecer uma relação coerente entre a ciência e a tecnologia, assim como uma compreensão abrangente sobre como o conhecimento científico se desenvolveu ao longo do tempo (ALLCHIN, 2012; DUARTE, 2004; LEDERMAN, ANTINK e BARTOS, 2014). Essa perspectiva está atrelada aos resultados de pesquisas em torno da epistemologia da ciência e do reflexo desta nas visões sobre a ciência e na aprendizagem dos conceitos científicos, que vem demonstrando que nossos estudantes não compreendem em um grau satisfatório o processo de construção e estabelecimento do conhecimento científico (MATTHEWS, 1995; DUARTE, 2004).

Diante disso, na década de 1960 houve uma tendência de aproximação dos estudos acerca das características do trabalho científico e a aprendizagem de ciências (DUARTE, 2004; MATTHEWS, 1995). De acordo com essa ideia, há abordagens com potencial para alcançar os objetivos estabelecidos, destacamos a contextualização histórica, a qual propõe a compreensão do processo de construção dos conceitos científicos por meio da inserção dos aspectos sócio históricos como uma alternativa didática, ou seja, propõe o estudo da Ciência enquanto construção humana envolta em processos permeados por avanços, erros e conflitos (MATTHEWS, 1995; ALLCHIN, 2012; OKI e MORADILLO, 2008; SILVA e MOURA, 2008; ANJOS e JUSTI, 2015). Neste sentido, alguns autores como Allchin (2004; 2012) e Moura (2008) apontam que o entendimento de episódios históricos no âmbito da ciência podem fornecer subsídios para discussões sobre a Natureza da Ciência em sala de aula, a medida em que proporciona uma visão mais dinâmica e detalhista sobre a atividade científica.

Matthews (1995) apresenta a Abordagem Contextual (AC), uma tendência voltada a contribuir com a educação científica unindo essa a História e Filosofia da Ciência (HFC) e considerando os elementos constitutivos da dinâmica social e cultural do fazer científico, os quais são característicos de cada contexto estudado, como as questões de ordem, política, econômica e ética que muitas vezes são inerentes à prática. Ainda assim, entendemos que a inserção de debates sobre HFC não deve consistir em mais um item a 
ser trabalhado na matéria, mas que sejam abordadas em conjunto com os conteúdos programáticos (MATTHEWS, 1995; ANJOS e JUSTI, 2015).

Logo, acreditamos na potencialidade da AC como uma maneira de discutir Ciência por meio da HFC, o que viria a permitir uma compreensão mais abrangente do conteúdo que se está sendo estudado. Buscando meios de investigação desta hipótese, este trabalho surgiu a partir do questionamento inicial em torno de uma temática específica: "quais aspectos históricos dos estudos sobre eletricidade de Michael Faraday poderiam contribuir, para que os estudantes construam explicações mais estruturadas sobre a Natureza Elétrica da Matéria?"

O interesse por este tema, de maneira mais pontual, advém da nossa percepção em torno da relevância dos estudos sobre eletricidade como fundamentais para a compreensão dos estudos sobre a matéria. Com base nisso, a primeira hipótese levantada é que a relação entre eletricidade e matéria já pode ser evidenciada a partir dos estudos de Michael Faraday. Uma segunda hipótese é que as concepções dos estudantes podem se aproximar das ideias apresentadas por este cientista e seus contemporâneos, tendo como base que algumas ideias aceitas no passado não são mais aceitas hoje enquanto outras são, compreender o porquê desse caráter transitório viria a contribuir para a aplicação mais coerente deste conhecimento a seus contextos específicos.

Considerando que há amplo consenso quanto à ideia de que as concepções alternativas são barreiras à apreensão do conhecimento científico, pois não são abandonadas pela simples apresentação do conhecimento científico escolar (EL-HANI e BIZZO, 2002). O que se propõe é que os estudantes compreendam que a ciência é uma dentre outras formas do saber, com seus parâmetros específicos de construção, consolidação e aplicação, esta meta pode ser alcançada através da Abordagem Contextual, pois fornece elementos que retratam a dimensão social, mediática, especulativa e concorrente das teorias na ciência (MATTHEWS, 2002).

\section{História da Ciência para um ensino contextual da ciência e uma possível relação com concepções alternativas}

Diversos autores vêm discutindo as contribuições da HFC para o Ensino de Ciências, e defendem a sua inserção nas práticas de sala de aula através das mais distintas estratégias, como o estudo dos Episódios Históricos (MATTHEWS, 1995; OKI e MORADILLO, 2008; SILVA e MOURA, 2008; ALLCHIN, 2004; 2014; ANJOS e JUSTI, 2015). A inserção desses componentes como meio para a compreensão da Natureza da Ciência pode proporcionar aos estudantes uma visão de ciência enquanto construção humana atrelada as suas questões sociais, culturais e éticas.

Compreendendo que a Abordagem Contextual seria uma perspectiva para ensinar Ciência por meio da HFC, podemos apontar algumas das potencialidades desta, tais como: fornece elementos do contexto de construção do conhecimento científico intrínseco a cada período histórico; pode combater à ideia de que a ciência é a detentora da verdade e que somente as teorias aceitas atualmente possuem importância no desenvolvimento da ciência; permite evidenciar que a ciência seria o produto das ideias dos indivíduos de 
uma determinada época, e não restrita apenas às ideias propagadas em biografias daqueles cientistas que obtiveram "sucesso" (DUARTE, 2004; SILVA, 2014; REIS, 2017). Dessa maneira, compreendemos também a necessidade e relevância de materiais adequados que permitam explorar essas questões na sala de aula, aspecto que tem sido um entrave à concretização dessas abordagens (DUARTE, 2004; MARTINS, 2006).

Martins $(2005 ; 2006)$ discute possíveis ideias equivocadas nas reconstruções históricas: a primeira diz respeito aquela repleta de datas e de informações que não têm relevância para o problema estudado; outra concepção é aquela denominada de interpretação whig da história também conhecida como anacrônica, consiste em estudar o passado com os olhos do presente, e, nessa concepção, há o enfoque apenas nos fatos que são aceitos atualmente esquecendo-se do contexto da época (ALLCHIN, 2004; 2014; MARTINS, 2005; 2006). Por isso, é necessário que o professor dê sentido aos eventos históricos buscando discutir o contexto em que os fenômenos ocorreram, assim como a vida e obra dos cientistas, em contraste aos relatos populares triunfais dos livros didáticos que costumam endeusa-los (ALLCHIN, 2004).

Alguns autores, como El-Hani e Bizzo (2002) apontam que a construção do conhecimento científico em sala de aula sofre influência dos modelos alternativos que os estudantes já possuem, logo, é possível inferir que a aprendizagem dos conceitos científicos ocorre mediante o estabelecimento de relações entre as concepções já existentes pelos alunos e o novo conhecimento que se está sendo estudado, desse modo, há também uma necessária atenção a tais concepções (SILVA e AMARAL, 2016).

Nesse contexto, cabe destacar o movimento de pesquisa iniciado na década de 70 , destinado a identificar e analisar no ensino de ciências as concepções anteriores ao ensino formal que os estudantes carregam consigo, as Concepções Alternativas (NARDI e GATTI, 2004). A importância de considerá-las baseou-se no pressuposto de que tais ideias não são abandonadas quando os estudantes adentram a sala de aula, visto que elas são utilizadas na representação da realidade social e cotidiana, configurando assim, como modelos explicativos para fenômenos que diferem das ideias científicas atuais (ARRUDA e VILLANI, 1994; NARDI e GATTI, 2004; SILVA e AMARAL, 2016). As ideias presentes nesse movimento são importantes segundo Matthews (2002), pois reconhece a HFC como uma alternativa potencial no Ensino de Ciências, para a compreensão da Ciência e de seus produtos (teorias, leis, linguagem, etc.), bem como dos seus parâmetros de validade, que podem sofre alterações ou até mesmo serem refutados para que outros mais amplos sejam inseridos no lugar.

Em um levantamento realizado sobre as concepções relacionadas à Estrutura da Matéria, notamos que muitos autores apontam que os estudantes atribuírem propriedades macroscópicas para explicar aspectos microscópicos da transformação da matéria; assim como a concepção de que "a natureza abomina o vazio", pois, apesar de utilizarem o modelo de partículas para representar a matéria, eles têm dificuldade em aceitar um modelo em que o vazio seja uma propriedade provável da matéria (MORTIMER, 1995). Destacam-se ainda as concepções em que os estudantes constroem suas explicações por influência de algum modelo específico veiculado nos livros didáticos ou na mídia em geral - Dalton, Thompson, Rutherford, Bohr - e se esquecem de considerar os 
parâmetros teóricos em que cada uma foi elaborada e a quais situações específicas se aplicam (FUKUI e PACCA, 1999; FRANÇA, MARCONDES e CARMO, 2009).

Quanto as ideias relacionadas a Formação e Caracterização da Entidade Íon, alusivas a relação entre carga (o elétron) e a formação de íons, destaca-se os resultados expostos por França, Marcondes e Carmo (2009), esses pesquisadores identificaram que existe certa rejeição dos estudantes à aceitação do modelo de transferência de elétrons entre os átomos.

Quanto a Condutibilidade Elétrica, Francisco Jr. e colaboradores (2005) identificaram que em um nível mais simples os estudantes atribuem esse fenômeno à capacidade que certos materiais têm de permitir a condução da eletricidade, mas sem mais explicações detalhadas, apenas conseguem estabelecer categorias de substâncias que conduzem ou não eletricidade, já as respostas de nível mais elaborado envolvem a presença de cargas elétricas como as responsáveis pela passagem da corrente.

Quanto as ideias sobre Corrente Elétrica, segundo Fukui e Pacca (1999), esta é compreendida pelos estudantes como o resultado da movimentação de cargas no interior do material condutor, o que, na linguagem dos estudantes, seria a presença de átomos negativos "versus" átomos positivos. Outros apresentam a concepção de que a corrente elétrica é oriunda da movimentação de cargas em sentido único, do polo positivo para o negativo, ou vice-versa; ou a transferência de elétrons entre os átomos do material condutor em um sentido único, entretanto para um único elétron e não para um conjunto deles.

Quanto ao papel das reações de oxirredução que são importantes para compreender a corrente que flui em um circuito eletroquímico, Pacca e colaboradores (2003) assim como Caramel e Pacca $(2004 ; 2011)$ argumentam que, apesar de a maioria dos estudantes atribuírem a origem da corrente às reações de oxirredução, não relacionam a movimentação das cargas na solução (íons) com a movimentação no material condutor (elétrons); eles focam na condução que ocorre em um dos circuitos (externo ou interno) e, para uma parcela, a corrente elétrica não se estabelece por meio de um circuito fechado, pois consideram apenas a corrente elétrica ou iônica.

Com base nisso, surge como uma possibilidade a ideia de apresentar aos estudantes o contexto sociocultural da construção da ciência, encarada como uma nova cultura (EL-HANI e BIZZO, 2002; MATTHEWS, 2002). Não se trata de promover aprendizagem através da ruptura das suas concepções prévias, mas iniciar os alunos na cultura científica por meio da AC (EL-HANI e BIZZO, 2002; MATTHEWS, 2002).

Assim posto, propomos como objetivo deste trabalho investigar como os constructos teóricos de Michael Faraday podem contribuir no âmbito do Ensino de Ciências, através da Abordagem Contextual, para compreensões cientificamente mais estruturadas quanto à Natureza Elétrica da Matéria, tendo como referência o levantamento das concepções dos estudantes expressas na literatura.

\section{Aspectos metodológicos}


O procedimento metodológico que utilizamos nessa pesquisa de natureza qualitativa foi por meio da Pesquisa Bibliográfica, que propõe a definição dos parâmetros de busca pelos documentos a serem analisados e que foi desencadeada com base em uma das etapas propostas por Lima e Mioto (2007), a saber: Investigação das Soluções.

A etapa definida por Lima e Mioto (2007) como Investigação das Soluções, foi caracterizada pela definição dos critérios para seleção das fontes relevantes para o estudo, a saber: (i) parâmetro temático - etapa de definição do tema a ser investigado, ou seja, documentos que retratam o contexto social de Michael Faraday e seus constructos teóricos sobre eletricidade; (ii) parâmetro linguístico - etapa de definição do idioma em que os documentos selecionados foram pesquisados, que para esta pesquisa foram documentos em língua inglesa, devido à possibilidade do levantamento de um maior número de trabalhos sobre Faraday; (iii) fontes consultadas - demarcação dos bancos de dados a serem consultados - a busca ocorreu nos seguintes bancos: Current Bibliography da Revista Isis, The British Journal for the History of Science, Bulletin for the History of Chemistry e Philosophical Transactions of the Royal Society of London, as três primeiras foram definidas com base em Martins (2005) ao apresenta-los como fontes ricas de trabalhos voltados a HFC e a última por ser rica fonte de trabalhos autorais deste cientista e; (iv) parâmetro cronológico - delimitação de publicações referentes ao período de "Faraday" e relatos científicos desse cientista ou de seus contemporâneos.

Após a Pesquisa Bibliográfica realizada, os artigos selecionados (ver Tabela 01) foram analisados por meio da Análise de Conteúdo proposta por Bardin (2016).

A Análise de Conteúdo se iniciou com a Leitura Flutuante, para conhecer os textos e as mensagens contidas neles, concretizada essa leitura preliminar, realizamos a codificação com base nas fontes, por exemplo, $C B \_01$ é o artigo 01 retirado da fonte Current Bibliography. Bardin (2016) orienta que seja definida a Unidade de Análise a ser considerada - menor unidade a ser extraída do texto -, dentre as possibilidades apresentadas pela autora, optamos pelo Tema, que consistiu em uma asserção sobre um determinado aspecto do assunto investigado, ou seja, desde uma pequena sentença, um conjunto delas ou um parágrafo.

Para o tratamento desses dados, utilizamos como fermenta auxiliar o software WebQDA, durante a etapa de categorização, etapa em que ocorreu o agrupamento das unidades temáticas analisadas em suas respectivas categorias, elaboradas a priori com base nos pressupostos da AC e nas concepções dos estudantes. 
Tabela 1 - Artigos encontrados com base nos critérios estabelecidos durante a Pesquisa Bibliográfica.

\begin{tabular}{|c|c|}
\hline Códic & Referência \\
\hline BHC_02 & $\begin{array}{l}\text { STOCK, J. T. The Pathway to the Laws of Electrolysis. Bulletin for the } \\
\text { History of Chemistry, v. } 11 \text {, p. } 86-92,1991 .\end{array}$ \\
\hline BJHS_01 & $\begin{array}{l}\text { LEVERE, T. H. Faraday, Matter, and Natural Theology: reflections on an } \\
\text { unpublished manuscript. The British Journal for the History of } \\
\text { Science, v. 4, n. 2, p. } 95-107,1968 \text {. }\end{array}$ \\
\hline BJHS_03 & $\begin{array}{l}\text { HEIMANN, P. M. Faraday's Theories of Matter and Electricity. The } \\
\text { British Journal for the History of Science, v. } 5 \text {, n. 3, p. 235-257, } \\
1971 .\end{array}$ \\
\hline & $\begin{array}{l}\text { CANTOR, G. Michael Faraday's Religion and its Relation to his Science. } \\
\text { Endeavour, v. 22, n. 3, p. 121-124, } 1998 .\end{array}$ \\
\hline & $\begin{array}{l}\text { McCABE, I. M.; THOMAS, J. M. The Bicentenary of the Birth of Michael } \\
\text { Faraday of the Royal Institution of Great Britain. Endeavour, v. 15, n. } \\
\text { 3, p. 133-140, } 1991 \text {. }\end{array}$ \\
\hline & $\begin{array}{l}\text { FARADAY, M. Experimental researches in electricity. third } \\
\text { series. Philosophical Transactions of the Royal Society of } \\
\text { London, v. 123, p. 23-54, } 1833\end{array}$ \\
\hline & $\begin{array}{l}\text { FARADAY, M. Experimental researches in electricity. fourth } \\
\text { series. Philosophical Transactions of the Royal Society of } \\
\text { London, v. 123, p. 507-522, } 1833 \text {. }\end{array}$ \\
\hline RSP_05 & $\begin{array}{l}\text { FARADAY, M. Experimental researches in electricity. fifth } \\
\text { series. Philosophical Transactions of the Royal Society of } \\
\text { London, v. 123, p. 675-710, } 1833 \text {. }\end{array}$ \\
\hline RSP_07 & $\begin{array}{l}\text { FARADAY, M. Experimental researches in electricity. Seventh } \\
\text { series. Philosophical Transactions of the Royal Society of } \\
\text { London, v. 124, p. } 77-122,1834 \text {. }\end{array}$ \\
\hline TFO_03 & $\begin{array}{l}\text { FARADAY, M. On Electric Conduction. Philosophical Magazine, n.4, } \\
\text { p.98-107, } 1855 \text {. }\end{array}$ \\
\hline TFO_01 & $\begin{array}{l}\text { FARADAY, M. On the Chemical and Contact Theories of the Voltaic } \\
\text { Baterry. Royal Institution, p.477-480, } 1839 .\end{array}$ \\
\hline TFO_02 & $\begin{array}{l}\text { FARADAY, M. Thoughts on Ray-Vibrations. Philosophical Magazine } \\
\text { Series 3, v. } 28, \text { n. } 188 \text {, p. } 345-350,1846 \text {. }\end{array}$ \\
\hline TFO_05 & $\begin{array}{l}\text { FARADAY, M. A Speculation Touching Electric Conduction and } \\
\text { Nature of Matter. Journal of the Franklin Institute, v. } 37 \text {, n. } 6 \text {, } \\
392-399,1844 .\end{array}$ \\
\hline
\end{tabular}

Fonte: os autores. 


\section{A construção das categorias}

O critério norteador para elaboração das categorias partiu da ideia de fornecer elementos sócio históricos e conceituais passíveis de inserção no Ensino de Ciências. Com base nas ideias de Matthews (1995), as categorias buscaram expor tanto os elementos internos da ciência, os quais se referem aos critérios teóricos e experimentais, assim como os elementos externos, que correspondem à influência dos aspectos sociais e religiosos como inerentes a atividade científica.

Os resultados percebidos durante a análise serão discutidos com base nas três categorias estabelecidas, a primeira é Influência externa na produção do conhecimento científico corresponde aos trechos existentes nos textos que abordam as questões externas a ciência (vida de Faraday e seus contemporâneos, questões econômicas, religiosas, políticas). Já a segunda categoria Mecanismos que teorizam a constituição da matéria, trata dos aspectos que revelam as proposições de teorias que buscavam explicar os mecanismos pelos quais as características da matéria se manifestavam. A última categoria, por sua vez, Composição da Matéria e sua relação com a eletricidade, corresponde aos trechos que permite traçar uma relação entre esses dois fenômenos, eletricidade e matéria.

\section{Influência externa na produção do conhecimento científico}

Uma das principais questões levantadas pela AC é a inserção dos aspectos sociais relacionados à construção do conhecimento científico, uma espécie de problematização do quanto as questões "fora" da Ciência tencionam o desenvolvimento dela própria ou vice-versa (MATTHEWS, 1995). Moura (2014) destaca que os aspectos externos à ciência influenciam a construção e consolidação do conhecimento científico à medida que a "atividade científica" se encontra imersa nesse contexto e sofre influência das questões sociais. Como eixo principal da discussão desta categoria, procuramos abordar três dentre tantos outros pontos significativos do contexto sócio histórico deste cientista: sua inserção na principal instituição científica da época (a Royal Society) e relação com cientistas influentes; a dinâmica da comunidade científica e a influência de suas crenças religiosas nas suas concepções científicas.

Como primeiro aspecto, destacamos o ambiente científico, tendo em vista que a Royal Institution era uma das principais instituições dedicadas à ciência da época, logo, a inserção de Faraday nesta comunidade foi fundamental para o desenvolvimento de suas pesquisas. Pode-se inferir que outro aspecto favorável ao desenvolvimento de Faraday como notável pesquisador foi à convivência com alguns dos mais renomados cientistas, em especial com o químico britânico Humphry Davy, cujas ideias tiveram influência significativa nas suas pesquisas. Essa dimensão social é retratada no recorte CB_04 e BHC_04.

CB_04 [...] Davy fez um tour de dezoito meses pelo continente acompanhado por Michael Faraday como seu assistente, secretário e criado. Faraday se beneficiou plenamente da experiência de conhecer homens da ciência famosos, notadamente Volta, Ampére, Arago, De La Rive, Dumas, Pictet e Gay Lussac. [tradução nossa]. 
Considerando essas ideias, entendemos que a compreensão da atividade científica pode ser potencializada pela apresentação dos elementos internos à ciência e que dizem respeito aos argumentos teóricos e às evidências experimentais disponíveis na época; assim como pelos elementos externos à ciência e que se referem às questões sociais, culturais e religiosas que permeiam os cientistas e os influenciam, posicionamento esse que vai ao encontro das ideias de Matthews (1995) quando propõe a Abordagem Contextual. No trecho em destaque, há uma percepção de que o contato de Faraday com Humphry Davy foi fundamental para a sua inserção no meio acadêmico. Além disso, há a menção aos "homens da ciência", o que nos leva a perceber a inexistência das mulheres na Academia.

Outros elementos relativos às questões externas à ciência e que influenciaram os constructos deste cientista foi à religião. O recorte BJHS_01 a seguir destaca a dimensão religiosa do seu pensamento:

BJHS_01 Deus tem prazer em trabalhar em sua criação material por leis, e essas leis são evidenciadas pela constância dos personagens da matéria e pela constância dos efeitos que ela produz. [tradução nossa].

A adesão de Faraday a um seguimento religioso tem origem em sua família, haja vista que os cientistas não estão alheios às influências da formação intelectual e social oriundas de seu seio familiar. Como destaca o recorte CB_02 a seguir, Faraday desde criança já estava inserido em um contexto religioso fortemente doutrinário, devido à influência da adesão de seu pai à seita denominada "Sandemanianos":

CB_02 Seu pai, que veio de perto de Clapham, em Yorkshire, pertencia a uma pequena seita cristã chamada Sandemanianos. Este grupo dissidente data de um cisma na Igreja da Escócia na década de 1720 e que no final do século 18, criou várias capelas, principalmente na Escócia, no norte da Inglaterra e Londres. [tradução nossa].

Para Faraday, as leis que governavam a natureza eram uma construção divina, e a ciência seria encarregada de desvendar os mecanismos em que a vontade de Deus se manifestava, além de que as ideias que não estivessem de acordo com os preceitos divinos eram consideradas incoerentes cientificamente. Como destacam Martins (2006) e Silva e Moura (2008), a ciência é uma entre tantas outras formas de explicar os fenômenos, e a religião se constitui como outra maneira de compreender a natureza, assim, considerando que a ciência não é neutra, tais elementos (científicos e espirituais) podem coexistir. Logo, os valores religiosos influenciaram sua postura social e crenças teóricas de Faraday, como destaca o trecho CB_02:

CB_02 Como um cristão sandemaniano, ele idealizou seu papel na comunidade científica como uma extensão natural de seus valores religiosos. Além disso, sugere-se que ele entendia o universo físico como uma economia natural divinamente ordenada; assim, sua ciência foi direcionada para determinar o modo como Deus criou o universo. [tradução nossa]. 
A discussão dessa categoria não retrata de forma completa todos os elementos da dinâmica social da vida de Michael Faraday, mas são elementos que proporcionam um vislumbre do panorama social da ciência e de seus "atores", em especial deste cientista, contudo, ainda é difícil, se não impossível, uma descrição fiel e completa de tudo aquilo que envolve o fazer ciência. Por isso, entendemos que a visão da ciência enquanto conhecimento produzido por gênios e resultante de um método rígido e algorítmico (método da descoberta) é uma visão não mais aceita. Moura (2014) argumenta que os cientistas utilizam imaginação, crenças pessoais e influências externas na construção de suas concepções teóricas, isto é, eles não estão alheios ao contexto de que fazem parte e nunca estão livres de influências externas.

\section{Mecanismos que teorizam a constituição da matéria}

A segunda categoria a ser discutida diz respeito aos modelos que no contexto sócio histórico de Faraday buscavam compreender os mecanismos em que a matéria manifestava suas transformações. Neste sentido, podemos trazer a tona o pressuposto de que a ciência está em constante transformação e que a atividade científica e os produtos dela oriundos (teorias, modelos, leis) são o resultado de um processo de debate, proposição de críticas e sucessivas (re)elaborações teóricas (MOURA, 2014; OKI e MORADILLO, 2008; SILVA e MOURA, 2008). É nesse contexto que propomos discutir essa categoria.

O século XVIII foi marcado pela "disputa" entre os mecanicistas e atomistas; nesse contexto, de acordo com a Filosofia Mecânica, o mecanismo em que as reações ocorriam seria explicado pelo comportamento de partículas imperceptíveis, e seus adeptos desenvolveram uma teoria em que as características atribuídas à matéria eram devido à atribuição de formas, polaridade (poderes de atração e repulsão) ou ao arranjo que cada partícula poderia assumir (DUNCAN, 1988; KNIGHT, 1966). O termo partícula, corpúsculo ou molécula era utilizado pelos adeptos da filosofia mecanicista para se referirem a uma pequena "porção" de matéria, e é nesse sentido que iremos usar tais termos quando nos referimos às ideias de Faraday.

No lado oposto, encontravam-se os adeptos da Teria Atômica apoiada principalmente pelos químicos que buscavam uma filosofia autônoma com seus parâmetros próprios de interpretação dos mecanismos e leis que governavam a matéria. Cabe citar a teoria atômica de John Dalton (1766-1844), que propôs uma filosofia em que as mudanças químicas ocorreriam devido à união e separação de partículas que compõem as substâncias, como os vários ácidos, bases e metais; os elementos de um mesmo átomo seriam idênticos entre si e de mesma massa, e a formação das mais diversas substâncias seria o resultado da união, em diferentes proporções, dos elementos que compõem a matéria (KNIGHT, 1966; DUNCAN, 1988).

Considerando a ciência e sua transitoriedade de ideias, como discutido por Moura (2014) e Martins (2006), as controvérsias são mecanismos inerentes à construção do conhecimento científico, pois tornam perceptível o papel do debate e das objeções que impulsionam as (re)avaliações das teorias em um processo impregnado tanto pelos fatores internos à ciência quanto pelos fatores externos. Assim, podemos enquadrar esse debate na taxonomia de controvérsia mais comum, a Controvérsia de Teoria, que ocorre 
quando duas ou mais teorias são apresentadas para explicar os mesmos fenômenos (NARASIMHAN, 2001).

Situando Faraday, suas convicções teóricas estavam voltadas para o modelo corpuscular da matéria, sua oposição é marcada pela não aceitação da existência de partículas com características mensuráveis, tendo em vista que a teoria atômica postulava a existência de entidades tão pequenas e diversas, que segundo ele, os mecanismos responsáveis pela origem de tantas substâncias não poderiam ser previstos. Tal posicionamento é expresso no recorte TFO_05:

TFO_05 A minha visão da constituição atômica da matéria predomina sobre aquela que considera o átomo como algo material com certo volume e que tem poderes maravilhosos de criação, que tem gerado daquele tempo ao presente, a capacidade de constituir, quando muitos átomos são reunidos em grupos, as diferentes substâncias cujos efeitos e propriedades observamos. [tradução nossa].

Posicionamento semelhante pode ser identificado nas concepções apresentadas por Mortimer (1995), ao identificar que os estudantes se utilizam de argumentos que refutam a existência de espaço na matéria. A principal oposição de Faraday à teoria atômica era a suposição da descontinuidade da matéria, e, como a teoria corpuscular tinha como ponto principal a interação entre os corpos para que fosse possível a ocorrência da transformação química, e a atração ou repulsão entre os corpos carregados eletricamente era um fator importante. A noção de interação tinha origem na teoria da gravidade de Newton (mecanicista), ou seja, a força era inversamente proporcional ao quadrado das distâncias e quanto maior a distância menor seria a força resultante, essa interação entre corpos celestes foi transposta para os constituintes da matéria (DUNCAN, 1988; KNIGHT, 1966).

Outro aspecto da teoria atômica que não corroborava com a concepção de matéria de Faraday era o mecanismo de condução, pois, segundo ele, seria o resultado da propagação da indução da polaridade através da interação entre partículas adjacentes. Uma questão surge em meio às suas concepções teóricas, a relação entre materiais isolantes e condutores. Se fosse admitida a descontinuidade da matéria e ela tivesse efeitos sobre a condução dos materiais, por que alguns materiais conduzem enquanto outros não? Quais os mecanismos possíveis? O recorte TFO_05, a seguir, apresenta o posicionamento de Faraday quanto a essa questão:

TFO_05 Portanto, a matéria será contínua e, ao considerar uma massa, não devemos supor uma distinção entre seus átomos e qualquer espaço de intervenção. Os poderes em torno dos centros dão a esses centros as propriedades dos átomos da matéria; e novamente estes poderes, quando muitos centros são agrupados em uma massa, dão a cada parte dessa massa as propriedades da matéria. Em tal visão, toda a contradição resultante da consideração do isolamento elétrico e da condução desaparece. [tradução nossa].

Assim, para Faraday a matéria é contínua em toda a sua extensão e não se deve supor a existência de espaços, pois, se considerarmos uma porção qualquer de matéria, a união de tais corpúsculos dá as características intrínsecas a cada material devido à 
interação das forças, que são resultantes da influência mútua entre uma partícula e suas vizinhas mais próximas. Portanto, ele considerou que, se existem compostos isolantes e condutores, e suas características dependem da forma como tais corpúsculos se unem.

Apesar de Faraday não admitir a descontinuidade da matéria, alguns fatos contribuíam para que tal posicionamento fosse repensado. A compressão ou exação de certos materiais devido à aplicação de pressão, calor ou uma redução da temperatura eram fatores que colaboravam para algumas incoerências da teoria mecanicista e a inexistência de espaços na matéria. Como destacado no trecho TFO_05, na sequência, Faraday então supõe que existem espaços intermediários, o que permite compreender os fenômenos da matéria sem recorrer a um modelo descontínuo da matéria.

TFO_05 Estes, embora agrupados e juntos por seus poderes, não se tocam, mas têm espaço intermediário, caso contrário, a pressão ou o frio não poderiam fazer com que um corpo se contraísse a um volume menor, nem o calor ou a tensão o tornar-se-iam maiores; em líquidos, esses átomos ou partículas devem se mover um em relação ao outro, e em vapores ou gases também estão presentes, mas se deslocam muito separadamente, embora ainda relacionados uns com os outros pelos seus poderes. [tradução nossa].

É importante destacar que há um longo caminho na aceitação das ideias tanto pela comunidade científica quanto pelo próprio cientista, visto que os modelos não surgem do nada, são construídos ao longo do tempo à medida que prós e contras são apresentados, e as ideias mais coerentes segundo os critérios adotados acabam se consolidando, e isso passa pela defesa dos seus adeptos diante da comunidade científica (MOURA, 2014; MARTINS, 2006).

No decorrer da elaboração de sua teoria, alguns elementos o fizeram questionar e repensar seus constructos teóricos, considerando sua forte rejeição à adesão de uma teoria particulada da matéria. Faraday então buscou elementos que permitissem continuar em seu programa experimental sem a necessidade de recorrer a um programa que não fosse pautado na teoria mecanicista, tendo encontrado em Roger Joseph Boscovich (1711-1787) os argumentos necessários. A teoria mecanicista elaborada por Boscovich, teorizava que a matéria seria composta por átomos pontuais (que seriam pequenas porções de matéria) que não tinham dimensão e que se repeliam a distâncias muito curtas, atraiam-se a grandes distâncias e a distâncias intermediárias alternavam-se entre esferas de atração e repulsão, assim as partículas seriam meros pontos que ocupam lugar no espaço (DUNCAN, 1988). A unidade TFO_05 demonstra a conversão de Faraday à teoria do átomo pontual de Boscovich:

TFO_05 [...] os átomos de Boscovich me parecem ter uma grande vantagem sobre a noção mais usual. Seus átomos, se entendendo corretamente, são meros centros de forças ou poderes, não partículas de matéria, nas quais os próprios poderes residem. [tradução nossa].

Diante dos elementos apresentados, destacamos que o debate entre distintas visões de mundo foi intenso, representando um período de disputa pública e persistente guiada por divergências e arcabouços teóricos considerados consistentes por seus defensores, principalmente entre os mecanicistas e os atomistas (NARASIMHAN, 2001). 
Faraday estava envolto nessa disputa e permaneceu cético quanto à teoria particulada da matéria. Em suas concepções teóricas, a noção da existência de partículas que seriam indivisíveis, a existência de espaços na matéria e a sua crença religiosa foram os principais pontos para sustentar sua oposição. Podemos inferir certa aproximação com as ideias apresentadas pelos estudantes, quando utilizam modelos distintos, mas sem considerar o seus parâmetros de construção e contextos em que são apropriados (FUKUI e PACCA, 1999; FRANÇA, MARCONDES e CARMO, 2009). As bases em que Faraday se apoiou foram válidas para seu contexto de pesquisa e proporcionaram avanços fundamentais para a teoria eletroquímica, em especial os mecanismos de condução e a relação quantidade de matéria e eletricidade, elementos que norteiam a terceira categoria.

\section{Composição da matéria e sua relação com a eletricidade}

No contexto de Faraday, várias teorias sobre a eletricidade foram propostas e estavam relacionadas à matéria, em especial os resultados oriundos dos fenômenos de eletrólise impulsionaram a pesquisa nessa área e envolveram o engajamento de uma parte significativa da comunidade científica, a qual buscava o esclarecimento quanto à origem desse fenômeno, aos prováveis mecanismos e à distinção entre materiais condutores e não condutores (OKI, 2000). Foi um período de debate que pode ser enquadrado como uma controvérsia da ciência, como proposto por Narasimhan (2001). Aqui iremos nos deter aos debates que contribuíram para compreender a natureza elétrica da matéria, mas sem perder de vista os constructos teóricos debatidos na categoria anterior, pois eletricidade e matéria foram dois campos que convergiram.

Por ser um fenômeno relacionado à matéria e como havia grupos que aderiram a bases filosóficas distintas (filosofia aristotélica, filosofia mecânica, filosofia química, etc.), as investigações resultaram em teorias com características distintas. Driver e colaboradores (1999) discutem que um determinado arcabouço de conhecimento não se estabelece enquanto a comunidade científica não entra em acordo sobre sua validade, e isso se torna parte da forma não problemática de ver as coisas. Assim, as ideias sofrem todo um processo de debate e aceitação e, quando aceitas pela maioria, constituem-se nos símbolos da ciência que são utilizados para explicar os fenômenos da natureza.

Em um primeiro momento, Faraday busca a unificação das teorias elétricas em uma base comum, ele partiu do seguinte princípio: se as "diferentes formas de eletricidade" como a voltaica e comum (obtida por friç̧ão) produziam os mesmos efeitos, então possivelmente teriam a mesma origem. Em seu programa experimental, o elemento que permitiria unificar as diferentes formas de eletricidade em um postulado único foi comparar os seus efeitos e pontuar as similaridades entre ambas. Percebemos assim, que durante 0 desenvolvimento científico, a construção das ideias depende da argumentação e da discordância de fatos, teorizações e crenças uns dos outros, podendo haver lutas entre si para impor ideias (DRIVER et al., 1999; NARASIMHAN, 2001; MARTINS, 2006).

O argumento utilizado para unificar a eletricidade foi à intensidade dos efeitos, pois, segundo Faraday, apesar de produzirem fenômenos semelhantes - como a atração e repulsão entre as partículas, decomposição e formação de novas substâncias -, os 
resultados não eram suficientemente próximos para que se pudesse inferir que eram oriundos de uma mesma forma de eletricidade. O principal parâmetro de comparação eram os fenômenos perceptíveis e mensuráveis, como a produção de gás ou deposição de material no recipiente; numa tentativa de ajustar os resultados, ele propôs que a diferença estava na intensidade dos efeitos que cada eletricidade poderia causar, como o próprio Faraday expressa na unidade RSP_03.

RSP_03 A conclusão geral que, a meu ver, deve ser extraída dessa coleção de fatos é que a eletricidade, seja qual for à fonte principal, é idêntica em sua natureza. Os fenômenos nos cinco tipos ou espécies citados diferem não em seu caráter, mas apenas em grau; e a esse respeito variam em proporção às circunstâncias variáveis de quantidade e intensidade, o que, com prazer, pode ser alterado em quase qualquer um dos tipos de eletricidade. [tradução nossa].

Com esses elementos, não queremos enfatizar que a construção do conhecimento não ocorre através de um conjunto de etapas pré-definidas estritamente, através das observações experimentais ou vice-versa; a relação entre teoria e experimento é complexa, e a observação feita pelo cientista não é imparcial, mas carrega consigo as concepções e expectativas de quem observa, e, apesar de não existir uma relação bem definida entre ambos, são importantes na construção do conhecimento científico (MOURA, 2014; SILVA e MOURA, 2008).

Essas ideias apontadas nos permitem iniciaremos uma análise do estudo de soluções capazes de conduzir eletricidade, uma vez que influenciaram significativamente à construção da teoria eletroquímica. Como expresso no recorte TFO_03 que se segue, uma das incógnitas que intrigavam os investigadores era a forma em que os eletrólitos (Faraday cunhou esse termo no decorrer de seus estudos sobre a condutividade de soluções) se encontravam em solução e como eles contribuíam para os efeitos de condutividade elétrica, bem como 0 que os diferenciava daqueles que não proporcionavam tal efeito:

TFO_03 [...] tornou-se uma questão saber se os corpos que formam a classe dos eletrólitos são condutores apenas enquanto estão passando por uma mudança adequada devido à ação da corrente elétrica; ou se eles podem se tornar assim como os metais e a madeira seca em diferentes graus, sem o acompanhamento de qualquer alteração química em seu interior. [tradução nossa].

Segundo Faraday, o poder de condução estava associado ao estado líquido e às características da partícula de matéria utilizada, e uma dessas características ele denominou de facilidade e se referia às "afinidades" entre as partículas que compõem a molécula, pois quanto maior a afinidade entre duas partículas mais força seria necessária para romper essa interação. O processo de condução estaria associado à água, que teria o seu grau de condutibilidade aumentado à medida que alguma impureza fosse adicionada a ela. $O$ poder de condução e a influência da adição à água são expressos respectivamente nos recortes RSP_05: 
RSP_05 É a opinião de vários filósofos que a presença de água é essencial na decomposição eletroquímica e também para a produção da eletricidade pela própria bateria voltaica [...]. A opinião, portanto, de que a água é necessária para a decomposição pode ter sido fundada na declaração feita por Sir HUMPHRY DAVY, de que "não há fluidos conhecidos, exceto tais como água, que podem ser transformados em um meio de conexão entre os metais e o aparelho voltaico. [tradução nossa].

A condutividade estaria associada ao estado das partículas ao serem dissolvidas em água, e Faraday propôs uma diferenciação quanto aos materiais sólidos condutores. Ele teorizou que a eletricidade causa no eletrólito uma mudança na estrutura da partícula e quanto maior a interação maior o seu poder de condução. Assim como não foi imediato o consenso quanto a natureza e efeitos destas partículas, os estudantes também possuem dificuldade para compreender o modelo de íon e sua função nos fenômenos eletroquímico (CARAMEL e PACCA, 2004, 2011; FUKUI e PACCA, 1999; FRANÇA, MARCONDES e CARMO, 2009).

De acordo com Faraday, nos materiais sólidos condutores, como os metais, a interação com a eletricidade não causa nenhuma alteração na estrutura do material, e a condução ocorreria segundo os mecanismos de propagação da força através da matéria. A sua concepção sobre a condução dos eletrólitos e dos materiais sólidos é destacada no recorte TFO_03:

TFO_03 O primeiro tipo de condução é distinguido como eletrolítico, a transferência da força elétrica parece estar essencialmente associada às mudanças químicas que ocorrem; o segundo tipo pode ser chamado de condução propriamente dita, e aí o ato de condução deixa o corpo, como ele o encontrou. [tradução nossa].

Faraday buscou não só unir em um mesmo fenômeno as teorias da eletricidade, mas também unir em um só mecanismo os fenômenos de decomposição eletroquímica. Segundo ele, os mesmos fenômenos poderiam ser obtidos através da eletricidade comum ou da eletricidade voltaica, e, ao contrário de cientistas como Ritter, De la Rive e Grotthuss, que acreditavam que tais efeitos eram o resultado da interação entre os polos e as partículas, semelhante a concepção identificada por Fukui e Pacca (1999). Faraday teorizou que as alterações são provocadas no interior das moléculas eletrolisadas. Assim, a corrente provocaria o enfraquecimento da afinidade entre as partículas que constituem a molécula, e os polos serviriam apenas como condutores da eletricidade, como descrito na unidade RSP_05:

RSP_05 Passando à consideração da decomposição eletroquímica, parece-me que o efeito é produzido por uma ação corpuscular interna, exercida de acordo com a direção da corrente elétrica, e que é devido à força adicionada ou devido a uma direção comum a afinidade química dos corpos presentes [...] e é porque a afinidade química comum é aliviada, enfraquecida ou parcialmente neutralizada pela influência da corrente elétrica em uma direção, paralela ao curso desta última, e reforçada ou adicionada na direção oposta, que as partículas combinadas têm tendência para seguir cursos opostos. [tradução nossa]. 
Os estudos de Faraday o levaram a estabelecer relações e padrões entre as fontes de eletricidade, as alterações na matéria decorrentes da passagem da corrente elétrica e a quantidade de eletricidade utilizada. $\mathrm{Na}$ unidade RSP_07 ele expõe suas concepções quanto à relação entre a quantidade de matéria decomposta proporcionalmente à quantidade de eletricidade aplicada ao material.

RSP_07 Na terceira série destas Pesquisas, depois de provar a identidade da eletricidade derivada de diferentes fontes e mostrando, por medição real, a quantidade extraordinária de eletricidade produzida por um arranjo volátil muito fraco (371. 376.), anunciei uma lei, derivada do experimento, que me pareceu da maior importância para a ciência da eletricidade em geral, e esse ramo é denominado particularmente de eletroquímica. A lei foi expressa assim: o poder químico de uma corrente de eletricidade está em proporção direta à quantidade absoluta de eletricidade que passa (377.). [tradução nossa].

Como apontam Driver e colaboradores (1999), um determinado arcabouço de conhecimento não se estabelece enquanto a comunidade científica não tiver entrado em acordo sobre sua validade, e isso se torna parte da forma não problemática de ver as coisas. Apesar de algumas teorizações propostas por Faraday não terem sido amplamente aceitas ou terem sido suprimidas por outras ideias, consideradas mais elaboradas, sua pesquisa contribuiu para a consolidação dos estudos eletroquímicos, principalmente a sua elaboração da lei que expressa que a corrente elétrica é diretamente proporcional à quantidade de matéria decomposta, ou seja, o estabelecimento explícito da relação entre eletricidade e matéria que mais à frente seria implementada pelas pesquisas de J.J. Thompson com a construção do modelo atômico constituído pela partícula "elétron". Assim, expor de forma mais objetiva a relação entre eletricidade e matéria pode contribuir para a construção pelos estudantes de modelos mais coerentes e que levem em consideração a dinâmica do fazer ciência e seus parâmetros de aplicação.

\section{Considerações Finais}

Com base nos aspectos apontados no texto pudemos obter categorias teóricas que além de evidenciar aspectos extra científicos inerentes ao contexto histórico no qual Faraday estava inserido, conseguimos também traçar uma relação entre os fenômenos elétricos e os mecanismos em torno de conceitos ligados a estrutura da matéria, sobretudo, das questões eletroquímicas e possíveis aproximações ou distanciamentos destas com algumas concepções dos alunos. Assim, acreditamos na relevância da Abordagem Contextual no ensino desses conceitos, uma vez que há a possibilidade de utilizar-se dessas ideias a fim de estabelecer relações com as mais variadas concepções dos estudantes durante o processo de construção de suas ideias no que tange a matéria, de um modo geral, destaca-se as visões a respeito da condutividade elétrica em solução, da corrente elétrica, assim como a formação de íons, ideias essas estudadas por Faraday e seus contemporâneos ao longo da HFC. Assim, podemos destacar a relevância deste trabalho para a Pesquisa em Ensino de Ciências, uma vez que apresenta resultados de uma pesquisa bibliográfica desenvolvida a partir de um recorte histórico em torno dos estudos de Faraday, apontando assim novas possibilidades de abordagem dos conteúdos sobre a matéria, a fim de torná-lo mais significativo para os estudantes e contribuir para 
um maior entendimento nas aulas de ciências. Logo, acreditamos que os relatos aqui expostos possam fornecer elementos que auxiliarão também no desenvolvimento dos conceitos relacionados à Natureza da Ciência, sendo possível ampliar e consolidar essas discussões tanto na Educação Superior como na educação básica, principalmente na abordagem da disciplina Química, tendo em vista as suas particularidades referentes aos aspectos eletroquímicos da matéria e inexistências dessas discussões durante a abordagem deste tópico.

\section{Agradecimentos}

Agradecemos o apoio financeiro do Conselho Nacional de Desenvolvimento Científico e Tecnológico (CNPq) e da Fundação de Apoio à Pesquisa e à Inovação Tecnológica do Estado de Sergipe (FAPITEC/SE).

\section{Referências}

ALLCHIN, D. Teaching the nature of science through scientific errors. Science Education, v. 96, n. 5, p. 904-926, 2012.

ALLCHIN, D. From science studies to scientific literacy: A view from the classroom. Science \& Education, v. 23, n. 9, p. 1911-1932, 2014.

ALLCHIN, D. Pseudohistory and pseudoscience. Science \& Education, v. 13, n. 3, p. 179-195, 2004.

ANJOS, M. M. O.; JUSTI, R. Favorecendo a Discussão de Alguns Aspectos de Natureza da Ciência no Ensino Médio. Revista Química Nova na Escola (Qnesc), v.37, n. Especial 1, p. 4-10, 2015.

ARRUDA, S. M; VILLANI, A. Mudança conceitual no ensino de ciências. Caderno Brasileiro de Ensino de Física, v. 11, n. 2, p. 88-99, 1994.

BARDIN, L. Análise de conteúdo (Edição revista e atualizada). Lisboa: Edições, v. 70, 2016.

CARAMEL, N. J. C.; PACCA, J. L. A. As concepções da condução elétrica e o funcionamento da pilha. In: Encontro Nacional de Pesquisa em Ensino de Física, 9., 2004, Jaboticatubas. Anais eletrônicos ... Jaboticatubas: 2004.

CARAMEL, N J.C.; PACCA, J. L. A. Concepções Alternativas em Eletroquímica e Circulação da Corrente Elétrica. Caderno Brasileiro de Ensino de Física, v.28, n.1, p.726, 2011.

DRIVER, R.; ASOKO, H.; LEACH, J.; MORTIMER, E.; SCOTT, P. Construindo Conhecimento Científico na Sala de Aula. Química Nova na Escola, v.9, p.31-40, 1999.

DUARTE, M. C. A História da Ciência na Prática de Professores Portugueses: implicações para a formação de professores de ciências. Ciência \& Educação, v.10, n.3, p.317-331, 2004. 
DUNCAN, A. M. Particles and eighteenth century concepts of chemical combination. The British Journal for the History of Science, v. 21, n. 4, p. 447-453, 1988.

EL-HANI, C. N.; BIZZO, N. M. V. Formas de construtivismo: mudança conceitual e construtivismo contextual. Ensaio Pesquisa em Educação em Ciências, v. 4, n. 1, 2002.

FRANÇA, A. C. G.; MARCONDES, M. E. R.; CARMO, M. P. Estrutura atômica e formação dos íons: uma análise das ideias dos alunos do $3^{\circ}$ ano do ensino médio. Química Nova na Escola, v. 31, n. 4, p. 275-282, 2009.

FUKUI, A.; PACCA, J. L. A. Modelo atômico e corrente elétrica na concepção dos estudantes. In: Encontro Nacional de Pesquisa em Educação em Ciências, 2., 1999, Valinhos. Anais eletrônicos ... Valinhos: 1999.

KNIGHT, D. M. The Atomic Theory and the Elements. Studies in Romanticism, p.185207, 1966.

LIMA, T. C. S.; MIOTO, R. C. T. Procedimentos Metodológicos na Construção do Conhecimento Científico: a pesquisa bibliográfica. Revista Katál, v.10, n.1, p.37-45, 2007.

LEDERMAN, N. G.; ANTINK, A.; BARTOS, S. Nature of science, scientific inquiry, and socio-scientific issues arising from genetics: A pathway to developing a scientifically literate citizenry. Science \& Education, v. 23, n. 2, p. 285-302, 2014.

MARTINS, L. A. C. P. História da ciência: objetos, métodos e problemas. Ciência \& Educação (Bauru), v.11, n.2, 2005.

MARTINS, R. A. A História das Ciências e seus Usos na Educação. In: SILVA, C. C. (Org.). História e Filosofia da Ciência. São Paulo: Ed. Livraria da Física, 2006.

MATTHEWS, M. R. História, Filosofia e Ensino de Ciências: a tendência atual de reaproximação. Caderno Catarinense de Ensino de Física, v.12, n.3, p.164-214, 1995.

MATTHEWS, M. R. Constructivism and science education: A further appraisal. Journal of Science Education and Technology, v. 11, n. 2, p. 121-134, 2002.

MORTIMER, E. F. Concepções atomistas dos estudantes. Química Nova na Escola, v. 1, n. 1, 1995.

MOURA, B. A. O que é a Natureza da Ciência e qual sua Relação com a História e Filosofia da Ciência. Revista Brasileira de História da Ciência, v. 7, n. 1, p.32-46, 2014.

NARASIMHAN, M. G. Controversy in Science. Journal of biosciences, v.26, n.3, p. 299304, 2001.

NARDI, R.; GATTI, S. R. T. Uma revisão sobre as investigações construtivistas nas últimas décadas: concepções espontâneas, mudança conceitual e ensino de ciências. Ensaio Pesquisa em Educação em Ciências, v. 6, n. 2, 2004.

OKI, M. C. M. A eletricidade e a Química. Química Nova na Escola, v.2, n.12, p.34-37, 2000.

OKI, M. C. M.; MORADILLO, E. F. O Ensino de História da Química: contribuindo para a compreensão da natureza da ciência. Ciência \& educação, v.14, n.1, p.67-88, 2008. 
PACCA, J. L. A.; FUKUI, A.; BUENO, M. C. F.; COSTA, R. H. P.; VALÉRIO, R. M.; MANCINI, S. Corrente Elétrica e Circuito Elétrico: algumas concepções do senso comum. Caderno Catarinense de Ensino de Física, v.20, n.2, p.149-165, agosto, 2003.

REIS, N. A. Abordagem Contextual no Âmbito do Processo Formativo no PIBID. 2017. 144f. Dissertação (Mestrado em Ensino de Ciências e Matemática) - Universidade Federal de Sergipe, São Cristóvão, 2017.

SILVA, E. L. Contribuições da elaboração de sequências de ensino-aprendizagem tratando das tendências interdisciplinaridade, cotidiano e história da ciência no âmbito da formação de professores da Universidade Federal de Sergipe. 2014. $184 \mathrm{f}$. Tese (Doutorado em Ensino, Filosofia e História das Ciências) - Instituto de Física, Universidade Federal da Bahia/ Universidade Estadual de Feira de Santana, Salvador, 2014.

SILVA, C. C.; MOURA, B. A. A Natureza da Ciência por meio do Estudo de Episódios Históricos: o caso da popularização da óptica newtoniana. Revista Brasileira de Ensino de Física, v.30, n.1, p.1602, 2008.

SILVA, J. R. R. T.; AMARAL, E. M. R. Concepções sobre Substância: relações entre contextos de origem e possíveis atribuições de sentidos. Química Nova na Escola, v.38, n.1, p.70-78, 2016.

Submissão: 18/01/2018

Aceite: $15 / 06 / 2018$ 